\title{
Rice Husk Ash as Raw Material for the Synthesis of Silicon and Potassium Slow-Release Fertilizer
}

\author{
Amanda A. França, ${ }^{a, b}$ Juliana Schultz, ${ }^{a}$ Roger Borges, ${ }^{a}$ Fernando Wypych ${ }^{a}$ and \\ Antonio S. Mangrich ${ }^{*, a, c}$
}

${ }^{a}$ Departamento de Química, Universidade Federal de Paraná, Centro Politécnico, CP 19081, 81531-980 Curitiba-PR, Brazil

${ }^{b}$ Department of Plant Nutrition, Technical University of Munich, Emil-Ramann-Str. 2, 85354 Freising, Germany

'Instituto Nacional de Ciência e Tecnologia de Energia e Meio Ambiente (INCT-E\&A), 40170-115 Salvador-BA, Brazil

Rice husk ash (RHA) is a waste material produced in large quantities in many regions worldwide, and its disposal can be problematic. This work describes a method for using RHA to synthesize silicon and potassium slow-release fertilizer. The extraction of silica from RHA was accomplished by alkaline leaching with $\mathrm{KOH}$. Different $\mathrm{KOH}$ concentrations and reaction times were evaluated and the best production of $\mathrm{K}_{2} \mathrm{SiO}_{3}$ solution was achieved using $6 \mathrm{~mol} \mathrm{~L}^{-1}$ and $6 \mathrm{~h}$, respectively. The fertilizer was synthesized by the reaction of $\mathrm{K}_{2} \mathrm{SiO}_{3}$ with $\mathrm{KAlO}_{2}$ in aqueous medium, followed by calcination at $500{ }^{\circ} \mathrm{C}$. X-ray fluorescence (XRF) and X-ray diffraction (XRD) analyses indicated that the fertilizer composition was similar to mineral kalsilite. Solubility essays indicated lower $\mathrm{K}^{+}$and $\mathrm{Si}^{4+}$ release percentage in neutral medium. Kinetic mechanisms of release tests can be well explained by the pseudo-second order model. The proposed synthesis seems to be a viable process offering economic and environmental benefits.

Keywords: rice husk ash, silicon, potassium, slow-release fertilizer

\section{Introduction}

Nowadays, one of the most important goal of agronomic management is the development of environmentalfriendly fertilizers, which promote a sustainable nutrient management to ensure growth crop yield. ${ }^{1}$ One method of reducing fertilizer nutrient losses involves the use of slowrelease fertilizers, which have been designed to gradually release nutrients to plants at a rate to coincide with the requirement of crops. The advantages of using slow-release fertilizers instead of the conventional type are various, such as the increased efficiency of the fertilizer, the continuous supply of nutrients for a prolonged period and a decrease of nutrient losses by volatilization and leaching out to surface and ground water. ${ }^{2,3}$

Potassium (K) is known as one of the most required nutrient during plant growth. $\mathrm{K}$ plays an important role in the energy state of the plant, translocation and storage

*e-mail: mangrich@ufpr.br of assimilates and maintenance of water in plant tissues. ${ }^{4}$ For many crops, silicon (Si) is also an important nutrient and its availability to plants is often associated to increase of crop yield. ${ }^{5}$

Plants under intensive cultivation that require high absorption of $\mathrm{Si}$, such as rice, sugar cane, and grasses in general, can quickly deplete the soluble Si content of soil. This element, therefore, needs to be replaced by fertilization. The application of Si fertilizer can influence plants in two ways: (i) by improvement of the fertility and chemical properties of the soil, and (ii) by direct effects on plant growth and development. ${ }^{6}$ Positive effects that have been reported include improved plant structure, such as upright leaves and stems, ${ }^{7}$ and increased resistance to fungi and insects due to deposition of Si under the plant cuticle. ${ }^{8}$

The high Si content of rice husk ash (RHA) has led to interest in its use as a source of $\mathrm{Si}$ for plants and for the production of numerous Si-based materials. ${ }^{9}$ RHA is generated after burning the rice husk, which is a waste from the rice processing industry, mainly used as a fuel 
to produce heat and steam required for the drying and parboiling of the rice grains. RHA contains high levels of silica (87-97\%), as well as some alkalis (1-5\%). ${ }^{9-11}$

The rice processing industry is a very important sector of global agribusiness and generates around 200 tons of waste biomass for every 1000 tons of harvest grains. ${ }^{12}$ Therefore, rice husk and RHA can be easily obtained in large quantities and are cheap raw materials, so their use is an attractive way of avoiding environmental problems due to improper disposal, while at the same time increasing profit margins. Furthermore, the agricultural use of a product containing RHA enables the recovery of valuable elements that were used previously for crop fertilization.

The aim of this study was therefore to develop a method to prepare a slow-release fertilizer containing silicon and potassium, using RHA as the raw material.

\section{Experimental}

\section{Chemical reagents}

All chemical reagents used in this study were analytical grade. Solutions were prepared using bidistilled water.

\section{Characterization of raw material and products}

Chemical characterization of RHA and the produced fertilizers was performed using X-ray fluorescence (XRF) analysis of compressed tablets of the samples, employing a PANalytical Axios Max spectrophotometer.

The pulverized samples were analyzed by X-ray powder diffraction (XRD), employing a Shimadzu XRD-6000 diffractometer, with $\mathrm{Cu} \mathrm{K} \alpha$ radiation ( $\lambda 1.5418 \AA$ ), dwell time of 2 degree $\mathrm{min}^{-1}$, voltage of $40 \mathrm{kV}$ and current of $30 \mathrm{~mA}$, at the interval $2 \theta$ from 10 to $80^{\circ}$ and 0.02 degree per step. The samples were placed and oriented by gently hand pressing on neutral glass sample holders. The qualitative phase analysis was performed with X'Pert HighScore software package (Philips, Netherlands) and the minerals were identified by comparison with the data bank of the International Centre for Diffraction Data (ICDD). The Rietveld refinement was applied to the RHA diffraction pattern in order to estimate the silica crystallinity index. ${ }^{13}$ The refinement was carried out using the GSAS/Expgui software..$^{14,15}$

\section{Silica extraction from RHA}

The silica was obtained by adding KOH (Sigma-Aldrich, Brazil) solution to RHA in a polypropylene beaker
$(150 \mathrm{~mL})$, using a ratio of $4.0 \mathrm{~mL} \mathrm{KOH}$ per $\mathrm{g}$ of RHA, under heating $\left(70{ }^{\circ} \mathrm{C}\right)$ and vigorous stirring, as described by Kalapathy et al. ${ }^{16}$ The mass of RHA used in each mixture was $5.0 \mathrm{~g}$. In order to identify the best conditions for the reaction, an evaluation was made of different $\mathrm{KOH}$ concentrations $\left(1,2,4,6,8\right.$ and $\left.10 \mathrm{~mol} \mathrm{~L}^{-1}\right)$ and reaction times (1, 2, 4 and $6 \mathrm{~h}$ ). After allowing the solution to cool at room temperature $\left(25^{\circ} \mathrm{C}\right)$, it was filtered using a quantitative filter paper (grade 54, Whatman) and the liquid potassium silicate was stored in a sealed polypropylene bottle $(50 \mathrm{~mL})$.

\section{Quantification of silica content}

Content of silica in the potassium silicate solution was quantified after its precipitation induced by the dropwise addition of $5 \mathrm{~mol} \mathrm{~L}^{-1} \mathrm{HCl}$ solution (Vetec, Brazil). The precipitation of silica began when the $\mathrm{pH}$ of the solution decreased to below $\mathrm{pH} 10$. After reaching $\mathrm{pH}$ ca. 7.0, the mixture was centrifuged at $3500 \mathrm{rpm}$ (relative centrifugal force of $1068.56 \times \mathrm{g}$ ) for $10 \mathrm{~min}$. The supernatant was discarded, water was added to the centrifuge tube, and the material was centrifuged again. This procedure was repeated three times. The solid gel separated by centrifugation was oven-dried at $110^{\circ} \mathrm{C}$ for $24 \mathrm{~h}$. Precipitated silica was characterized by $\mathrm{XRF}$ in order to avoid weighing errors resulting from possible contamination with the by-product potassium sulfate salt, which can remain even after repeated washings. The XRF measurements were performed in a Philips model PW2400. The results were interpreted with the semi-Q Philips software and were normalized to $100 \%$. All assays were performed in triplicate.

\section{Experimental design and statistical analysis}

Precipitated silica yielded from RHA $\left(\eta_{(\%)}\right)$ was determined using the following equation 1 :

$\eta_{(\%)}=\frac{\text { precipitated silica mass }}{\text { silica mass in RHA }} \times 100$

The silica mass in RHA was determined by using XRF, as described above.

Data were treated using analysis of variance (ANOVA) and the averages of the replicates were compared using Tukey's test at $5 \%$ probability. The objective was to choose the best conditions for the silica extraction, considering the concentration of $\mathrm{KOH}$ solution and the reaction time. The statistical calculations were performed using R Statistical software (R Foundation). 


\section{Synthesis of fertilizers}

Potassium silicate solution was produced using the best extraction conditions previously selected. The fertilizers FERT1 and FERT2 were synthesized by reaction between solutions of potassium silicate as obtained above and potassium aluminate $\left(\mathrm{KAlO}_{2}\right)$, as described by Fernandes et al. ${ }^{17}$ (modified). $\mathrm{KAlO}_{2}$ solution was prepared by reacting $50.0 \mathrm{~g}$ of aluminum scrap and $1.0 \mathrm{~L}$ of $\mathrm{KOH}$ solution $\left(1.0 \mathrm{~mol} \mathrm{~L}^{-1}\right)$, performed in polypropylene beaker (2000 $\mathrm{mL}$ ) under an extraction hood due to the release of hydrogen gas. The solution was stored in a sealed polypropylene bottle $(1500 \mathrm{~mL})$.

FERT1 synthesis was performed using $120.0 \mathrm{~mL}$ of potassium silicate solution and $100.0 \mathrm{~mL}$ of potassium aluminate solution, under continuous stirring at $70^{\circ} \mathrm{C}$. After formation of a gel, manual agitation with a polypropylene stick was continued for a further $5 \mathrm{~min}$. The produced gel was filtered in a qualitative filter paper (grade 5, Whatman), washed with distilled water and subsequently dried in an oven at $110{ }^{\circ} \mathrm{C}$ for $24 \mathrm{~h}$. A portion of FERT1 was calcined at $500{ }^{\circ} \mathrm{C}$ for $4 \mathrm{~h}$ in a muffle furnace, with heating from room temperature $\left(25^{\circ} \mathrm{C}\right)$ to $500{ }^{\circ} \mathrm{C}$ at a rate of $10{ }^{\circ} \mathrm{C} \mathrm{min}{ }^{-1}$ to produce FERT2.

\section{Study of fertilizer release}

A preliminary evaluation was made in order to quantify the solubility of $\mathrm{K}$ from FERT1 and FERT2. The assay was performed at $25^{\circ} \mathrm{C}$ in a temperature-controlled incubator from Tecnal model TCM44. In a beaker $(250 \mathrm{~mL}), 1.00 \mathrm{~g}$ of fertilizer was added to $200 \mathrm{~mL}$ of distilled water. The mixtures were kept in the incubator for $6 \mathrm{~h}$, without stirring, followed by filtration using quantitative filter paper (ashless, grade 40, Whatman). The retained solid material was discarded, and the filtered solution was analyzed using a Digimed flame photometer model NK-2000 to determine the potassium ion content, being the essay performed in triplicate. The calibration of the flame photometer was done by using a potassium standard solution in different concentrations.

An additional solubility test was performed with the fertilizer that showed the best result, i.e., the one that presented lower rate of potassium release. Fertilizer solubility curves were built using six different times: 3, 6, 12, 24, 36 and $48 \mathrm{~h}$, and three different solvents: bidistilled water, $0.1 \mathrm{~mol} \mathrm{~L}^{-1}$ citric acid solution and $0.5 \mathrm{~mol} \mathrm{~L}^{-1}$ hydrochloric acid solution, as described by Mangrich et al. ${ }^{18}$ Citric acid solution was used in order to simulate the organic acids present in soil solutions. Portions $(1.0 \mathrm{~g})$ of the dry fertilizer samples were added to $150 \mathrm{~mL}$ of $\mathrm{HCl}$ solution, $150 \mathrm{~mL}$ of citric acid solution or $200 \mathrm{~mL}$ of bidistilled water. The mixtures were prepared in three different beakers $(250 \mathrm{~mL})$ and kept in an incubator during the different test period. ${ }^{19}$ The mixtures were subsequently filtered using a quantitative filter paper (ashless, grade 40, Whatman), the retained solid material was discarded, and the filtered solution was stored in a refrigerator.

Measurements of the $\mathrm{K}$ and $\mathrm{Si}$ contents of the filtered solutions were performed using an inductively coupled plasma optical emission spectrometry (ICP OES equipment from Varian model 720-ES). The following ICP OES parameters were used: argon, RF generator power of $1.2 \mathrm{~kW}$, plasma gas flow rate of $15 \mathrm{~L} \mathrm{~min}^{-1}$, auxiliary gas flow rate $1.5 \mathrm{~L} \mathrm{~min}^{-1}$, nebulizer pressure of $200 \mathrm{kPa}$ and

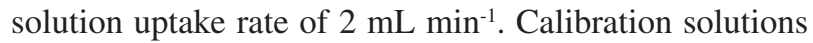
were prepared from serial dilutions of ICP-standard of $\mathrm{Si}$ and K (SpecSol). The concentration of the calibration solution ranged from 2.5 to $25.0 \mathrm{mg} \mathrm{L}^{-1}$. Each calibration curve was obtained by using six calibration solutions with different concentrations. The emission lines for the analysis by ICP OES were chosen according to previous interference studies that were $766.491 \mathrm{~nm}$ for K and $251.611 \mathrm{~nm}$ for Si. Calibration was checked initially and then after the analysis of every 20 samples, and in case of deviation of more than $10 \%$, the equipment was recalibrated.

In order to describe the potassium and silicon release behavior from the fertilizer in bidistilled water, citric acid solution and hydrochloric acid solution, kinetic parameters were calculated using the results of the solubility tests performed as described above. The study of the sorption kinetics can provide valuable insights into the reaction pathways and into the mechanism of sorption reactions. ${ }^{20}$ Three different models were tested in order to assess which one was the most suitable for describing the kinetic mechanism. The models used in the investigation were the pseudo-first order, ${ }^{21}$ pseudo-second order ${ }^{22}$ and intra-particle diffusion. ${ }^{23}$ The equations corresponding to each model are presented in Table 1.

\section{Results and Discussion}

\section{Raw material characterization}

The concentrations of chemical elements (expressed in their oxide forms) present in RHA were determined using XRF analysis. As expected, the main component of the RHA was silica $\left(\mathrm{SiO}_{2}\right)$ with $92.3 \%$ content. The root mean square (RMS) of the XRF results was 0.035 . The sum before normalization was $86.5 \%$.

Potassium and phosphorus oxides, normally derived from the fertilizers used in rice plantations, represented 
Table 1. Linearized form of the equations of the used kinetic models

\begin{tabular}{lc}
\hline Kinetic model & Linearized form \\
\hline Pseudo-first order & $\log \left(\mathrm{q}_{\mathrm{e}}-\mathrm{q}_{\mathrm{t}}\right)=\log \left(\mathrm{q}_{\mathrm{e}}\right)-\frac{\mathrm{k}_{\mathrm{I}}}{2.303} \mathrm{t}$ \\
Pseudo-second order & $\frac{\mathrm{t}}{\mathrm{q}_{\mathrm{t}}}=\frac{1}{\mathrm{k}_{\mathrm{II}} \mathrm{q}_{\mathrm{c}}^{2}}+\frac{1}{\mathrm{q}_{\mathrm{c}}} \mathrm{t}$ \\
Intra-particle diffusion & $\mathrm{q}_{\mathrm{t}}=\mathrm{k}_{\mathrm{d}} \mathrm{t}^{\frac{1}{2}}+\mathrm{C}$ \\
\hline
\end{tabular}

$\mathrm{t}$ : time; $\mathrm{q}_{\mathrm{e}}$ : ion desorbed at equilibrium time $\mathrm{t} ; \mathrm{q}_{\mathrm{t}}$ : ion desorbed at time $\mathrm{t}$; $\mathrm{k}$ : desorbed rate constant; $\mathrm{C}$ : ion concentration in solution.

1.4 and $0.7 \%$ of RHA, respectively. Other oxides were from the soil pool and included calcium $(0.8 \%)$, magnesium $(0.4 \%)$, manganese $(0.2 \%)$ and sodium $(0.1 \%)$. The concentrations of $\mathrm{CO}_{2}, \mathrm{Al}_{2} \mathrm{O}_{3}$ and $\mathrm{Fe}_{2} \mathrm{O}_{3}$ were 3.9, 0.2 and $0.1 \%$, respectively.

The X-ray diffraction pattern of RHA (Figure 1) stands together with the results of the calculation using the Rietveld method. As shown in Figure 1, RHA essentially consisted of amorphous silica and cristobalite. The occurrence of crystallization in some parts of RHA was due to the high temperatures reached during the firing, above $800{ }^{\circ} \mathrm{C}$, at which crystallization is likely to start in RHA silica. ${ }^{24}$

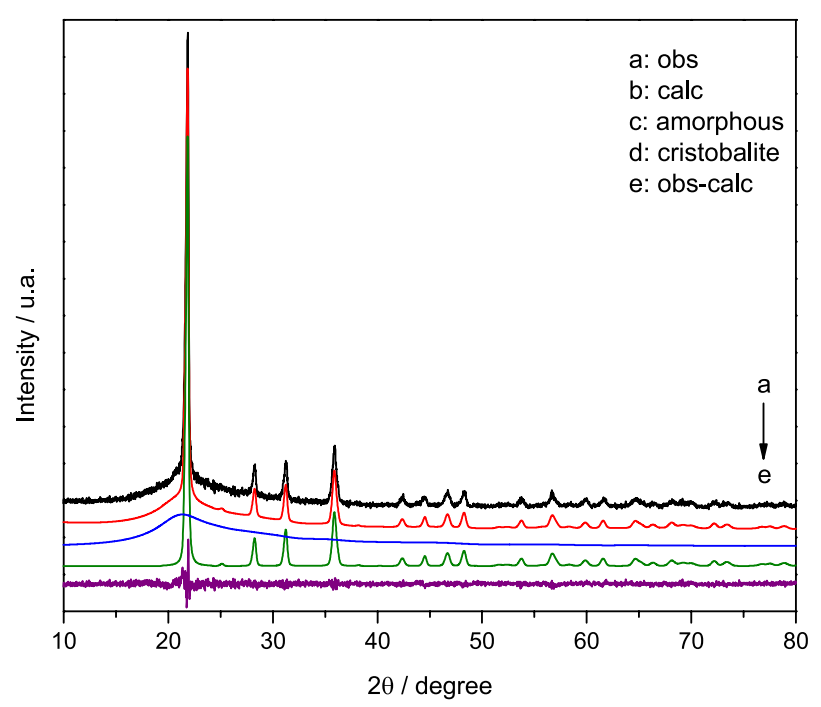

Figure 1. XRD diffraction pattern of RHA and refinement curves by the Rietveld method. The curves correspond to: (a) the experimental XRD pattern, (b) the XRD pattern calculated using the Rietveld intensity function, (c) the contribution of the cristobalite phase, and (d) the contribution of the amorphous phase to the overall profile. Line (e) represents the difference between the observed and calculated intensity values $\left(\mathrm{y}_{\mathrm{obs}}-\mathrm{y}_{\text {calc }}\right)$.

The numerical indicators that measure the quality of the fits between the intensities are the Bragg (Rwp) and expected (Rexp) factors. The Rwp measures the quality of the fit between the observed and calculated intensities, while the Rexp measures the quality of the collected intensities. In this study, the indicator values were 11.13 and $9.84 \%$ for Rwp and Rexp, respectively. Since the Rwp and Rexp values were close (Rwp / Rexp ratio of 1.1311), the refinement is considered satisfactory. The Rietveld analysis indicated that the percentage of amorphous silica and cristobalite was of 47 and 53\%, respectively, with lattice parameters $\mathrm{a}=\mathrm{b}=4.989 \pm 0.006 \AA$ and $\mathrm{c}=6.953 \pm 0.008 \AA$.

\section{Quantification of silica obtained from RHA}

The amounts of silica precipitated from RHA under the different reaction conditions are shown in Figure 2. The average quantity of precipitated silica varied according to the treatment used and increased with reaction time for all $\mathrm{KOH}$ concentrations up to $6 \mathrm{~mol} \mathrm{~L}^{-1}$. For concentration greater than $6 \mathrm{~mol} \mathrm{~L}^{-1}$, the amount of precipitated silica became almost constant. The maximum precipitation yield was $98 \%$ of the RHA silica.

\section{Statistical analysis}

The results obtained in the silica precipitation tests were compared by ANOVA analysis, which revealed significant differences between the average yields. Tukey's test for comparison of averages was applied and the results are shown in Figure 2.

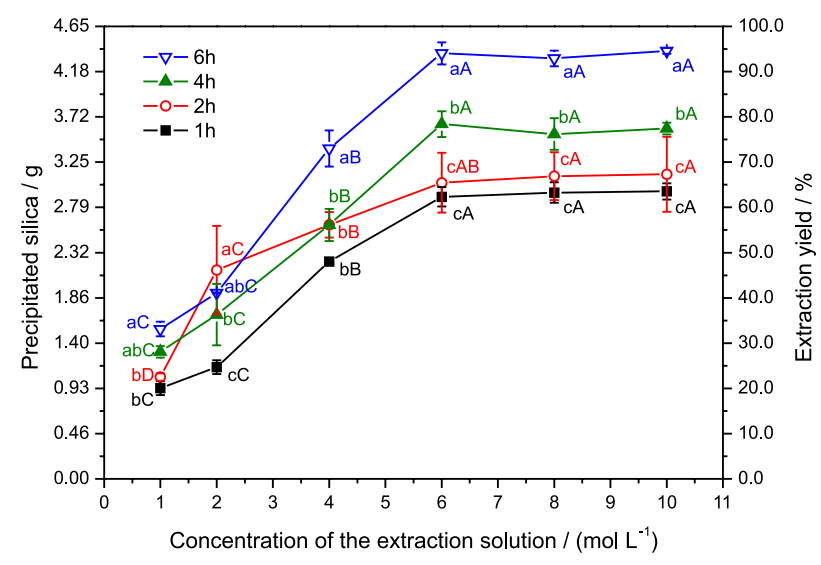

Figure 2. Quantification of precipitated silica in terms of mass and percentage extraction yield for different reaction periods $(1,2,4$ and $6 \mathrm{~h}$ ), and $\mathrm{KOH}$ solution concentrations. The small letters represent the Tukey's test applied to the average of the precipitated silica in the tests performed in triplicate. Averages followed by the same letters (lower case letters for $\mathrm{KOH}$ solution concentrations and upper case letters for reaction period) are not significantly different at the $95 \%$ level.

The treatments with higher yield of silica, which did not differ significantly (identified by the letters aA in Figure 2) 
were concentration $\times$ time: $6 \mathrm{~mol} \mathrm{~L}^{-1} \times 6 \mathrm{~h} ; 8 \mathrm{~mol} \mathrm{~L}^{-1} \times 6 \mathrm{~h}$ and $10 \mathrm{~mol} \mathrm{~L}^{-1} \times 6 \mathrm{~h}$. Hence, the treatment using $6 \mathrm{~mol} \mathrm{~L}^{-1}$ of $\mathrm{KOH}$ solution and a reaction time of $6 \mathrm{~h}$ was chosen as the first step of the fertilizer synthesis.

\section{Preliminary study of potassium release}

The preliminary study of fertilizer solubility was performed in the flame photometer. The average concentrations of potassium found in the solubility tests were $746.3 \pm 25.1$ and $503.33 \pm 5.7 \mathrm{mg} \mathrm{L}^{-1}$ for FERT1 and FERT2, respectively. For a period of 6 h, FERT2 showed a lower percentage of potassium release (29.6\%) compared to FERT1 (43.9\%), indicating that the heat treatment used for FERT2 synthesis was able to decrease $\mathrm{K}$ release in water for $6 \mathrm{~h}$ by about $67.5 \%$.

In recent studies, lower rates of potassium release were obtained by using higher calcination temperature. Mangrich et al. ${ }^{25}$ prepared a kalsilite-type $\left(\alpha-\mathrm{K}_{2} \mathrm{MgSi}_{3} \mathrm{O}_{8}\right)$ mineral structure from mixtures of potassium carbonate (commercial salt), lime shale and oil-shale fines, using a calcination process at $900{ }^{\circ} \mathrm{C}$. The solubilities of the product, expressed as a percentage of $\mathrm{K}_{2} \mathrm{O}$, were $30.3 \%$ in $0.5 \mathrm{~mol} \mathrm{~L}^{-1} \mathrm{HCl}, 23.2 \%$ in $0.1 \mathrm{~mol} \mathrm{~L}^{-1}$ citric acid and $6.9 \%$ in $\mathrm{H}_{2} \mathrm{O}$. Ma et al. ${ }^{26}$ synthesized a hexagonal kalsilite with an irregular blocky morphology through a sintering process, by heating at $900{ }^{\circ} \mathrm{C}$ for $2 \mathrm{~h}$. The solubilities of $\mathrm{K}_{2} \mathrm{O}$ from $\mathrm{K}_{2} \mathrm{MgSi}_{3} \mathrm{O}_{8}$ in $0.50 \mathrm{~mol} \mathrm{~L}^{-1} \mathrm{HCl}$ and $0.10 \mathrm{~mol} \mathrm{~L}^{-1}$ citric acid solutions were 38.94 and $23.58 \%$, respectively. For this reason, the calcination process proved to be an important step during the development of the fertilizer with slow-release behavior.

As the aim of this work was to develop a fertilizer with slow-release properties, therefore only the chemical characterization of FERT2 is described in this paper.

\section{Fertilizer characterization}

The results of XRF analysis showed that the silica content of the FERT2 fertilizer was $38.0 \%$. The potassium and aluminum contents, expressed in terms of oxides, were 33.9 and $24.8 \%$, respectively. The concentrations of other elements determined were $3.1,0.1$ and $0.1 \%$ of $\mathrm{CO}_{2}, \mathrm{P}_{2} \mathrm{O}_{5}$ and $\mathrm{Na}_{2} \mathrm{O}$, respectively.

The X-ray diffraction pattern of FERT2 shown in Figure 3 presents the main diffraction peaks and intensities coincident with the structure of hydrated potassium aluminum silicate $\left(\mathrm{KAlSiO}_{4} \cdot 5 \mathrm{H}_{2} \mathrm{O}\right) .{ }^{27}$ This mineral, known as kalsilite, is classified as a feldspathoid, which is a group of minerals chemically similar to feldspars, but with lower proportions of silica. They are characterized as being unsaturated in silica and rich in alkalis. ${ }^{28}$ The other peaks with lower intensity were not identified by using X'Pert HighScore software package.

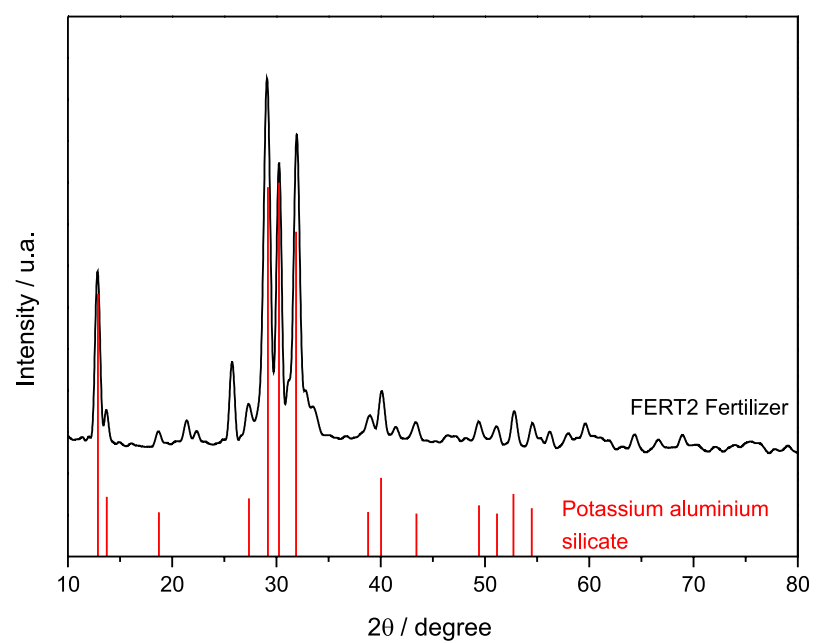

Figure 3. X-ray diffraction pattern of FERT2. The lower bars indicate the diffraction peaks of the potassium aluminium silicate (code: 38-0216 in X'Pert HighScore), described by Kosorukov and Nadel ${ }^{27}$ (ICDD reference pattern).

\section{$\mathrm{Si}$ and $\mathrm{K}$ release studies}

The results of the ICP OES analysis of solubilized $\mathrm{Si}$ and $\mathrm{K}$ in the liquid extracts are shown in Figure 4 and Figure 5. The Si release curve indicated lower solubility in a neutral medium, around to $0 \%$ (Figure 4). The release of Si was higher in both acid solutions, reaching around $50 \%$ for $48 \mathrm{~h}$. Approximately $32 \%$ of the potassium were into water as $\mathrm{K}^{+}$ions for a $48 \mathrm{~h}$ period (Figure 5). In acidic solution, the release of $\mathrm{K}^{+}$was higher, with almost total release in citric acid solution. The slower solubility of the fertilizer in the citric acidic solution indicates that it is a characteristic of the initial attack. However, thermodynamically, the citric

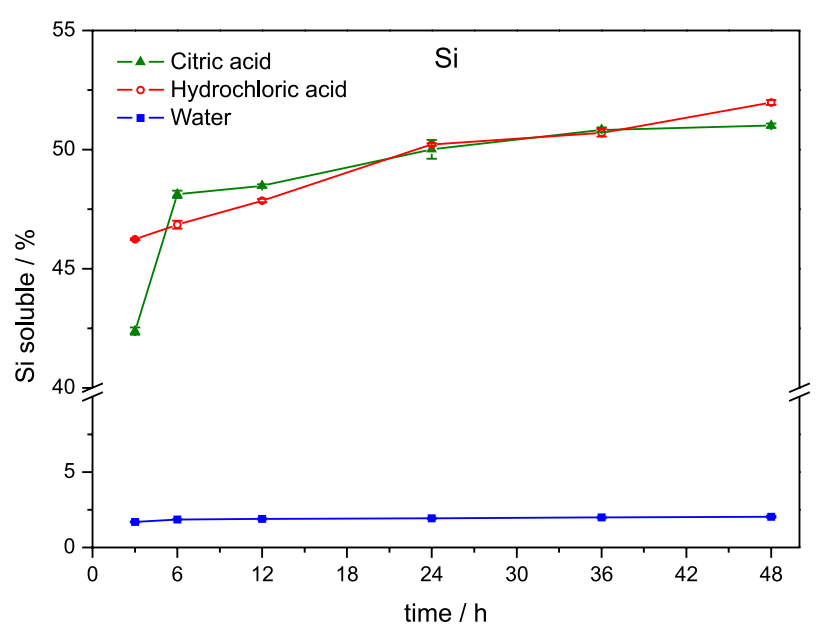

Figure 4. FERT2 release curves for Si using three solutions: distilled water, hydrochloric acid $\left(0.5 \mathrm{~mol} \mathrm{~L}^{-1}\right)$ and citric acid $\left(0.1 \mathrm{~mol} \mathrm{~L}^{-1}\right)$. 


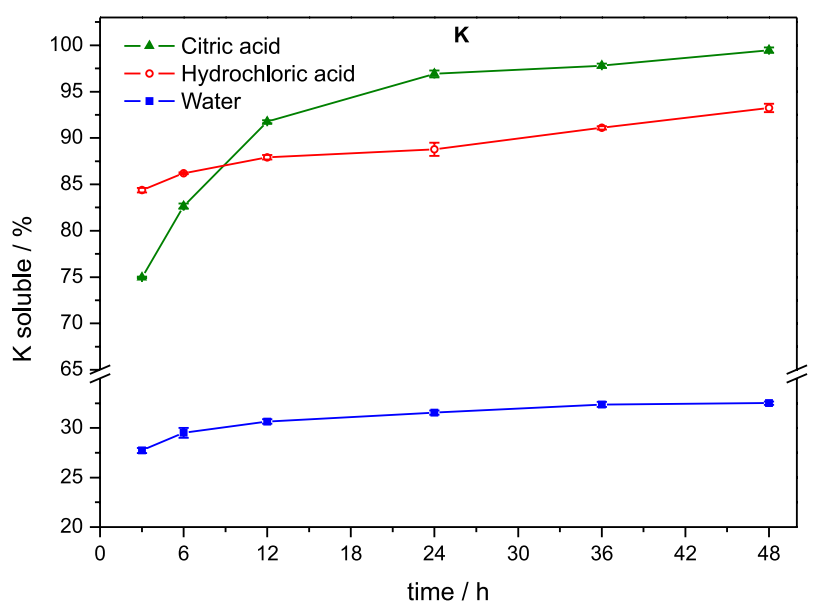

Figure 5. FERT2 release curves for K using three solutions: distilled water, hydrochloric acid $\left(0.5 \mathrm{~mol} \mathrm{~L}^{-1}\right)$ and citric acid $\left(0.1 \mathrm{~mol} \mathrm{~L}^{-1}\right)$.

acid is better than $\mathrm{HCl}$ due to the formation of more stable complex $\left(\mathrm{C}_{6} \mathrm{H}_{5} \mathrm{~K}_{3} \mathrm{O}_{7}\right)$. ${ }^{26}$

The kinetic parameters calculated and measured in order to describe the behavior of $\mathrm{Si}$ and $\mathrm{K}$ release from FERT2 are shown in Table 2. The pseudo second-order model provided the best correlation to describe the release mechanism of Si and $\mathrm{K}$ into the three different liquid extracts. In addition, this model also fits the experimental data well, i.e., $\mathrm{q}_{\mathrm{e}}$ (ion desorbed at equilibrium time) values calculated from linear form are in accordance with experimental $\mathrm{q}_{\mathrm{e}}$ values for both elements studied, especially in bidistilled water. The kinetic parameters for Si release in bidistilled water indicated a slower behavior than in acid solutions, as can be seen in Figure 4. This behavior can be explained because acid solutions have higher concentration of hydrogen ion that can react with silicate producing silicic acid, which is the most soluble form of Si. Citric acid solution, even if diluted, has relatively high acidity ( $\mathrm{pH}$ ca. 2.3).

The desorbed constant rates $(\mathrm{k})$ for $\mathrm{K}$ release essays in bidistilled water and $\mathrm{HCl}$ have close values on the same scale of magnitude, whereas the test in acid citric presented the smaller rate of all essays (Table 2 and Figure 5). In pure water, the experimental and calculated $\mathrm{K}^{+}$release were smaller probably due to the possible similarity between the structures of FERT2 and kalsilite $\left(\mathrm{KAlSiO}_{4}\right)$ mineral, as shown in Figure 3. This mineral is formed by $\mathrm{Si}-\mathrm{O}-\mathrm{Al}$ bonds between silicon-oxygen $\left(\mathrm{SiO}_{4}\right)$ and aluminumoxygen $\left(\mathrm{AlO}_{4}^{-}\right)$tetrahedrons. The potassium ions form chemical bonds with oxide ions $\left(\mathrm{O}^{2-}\right)$ from the tetrahedrons, hence becoming strongly bonded to the structure and difficult to release.

\section{Conclusion}

The findings of this study demonstrate the potential of RHA as a raw material to synthesize a Si and $\mathrm{K}$ slow-release fertilizer. The process used to extract the silica from RHA was able to precipitate more than $95 \%$ of the silica. The fertilizer synthesized has a chemistry composition and $\mathrm{X}$-ray diffraction pattern similar to the hydrated potassium aluminum silicate $\left(\mathrm{KAlSiO}_{4} \cdot 5 \mathrm{H}_{2} \mathrm{O}\right)$, known as kalsilite. The essays of $\mathrm{Si}$ and $\mathrm{K}$ release from the fertilizer in bidistilled water, citric acid and hydrochloric acid solutions showed a small solubility of the fertilizer in neutral environment. In acid solutions, the releases of $\mathrm{Si}$ and $\mathrm{K}$ were higher, with more than $50 \%$ of $\mathrm{Si}$ release and almost total $\mathrm{K}$ release in $48 \mathrm{~h}$. The pseudo second-order model was suitable for describing the kinetic mechanism, being the coefficient of determination greater than 0.9993 for all essays. Since RHA is a waste generated in large quantities and can cause environmental issues due to improper disposal, the developed process seems to be a viable way of using RHA waste and metal filings, offering considerable environmental benefits. The product here prepared took into consideration knowledge of chemical structure and environmental care. In our view, the use of a waste to

Table 2. Kinetic pseudo-second order model for Si and K nutrient release

\begin{tabular}{|c|c|c|c|}
\hline Kinetic parameter & Bidistilled water & $\mathrm{HCl}$ & Acid citric \\
\hline \multicolumn{4}{|c|}{ Silicon } \\
\hline $\mathrm{k}_{\mathrm{II}} / \min ^{-1}$ & $4.261 \times 10^{-2}$ & $1.157 \times 10^{-3}$ & $2.025 \times 10^{-3}$ \\
\hline $\mathrm{q}_{\mathrm{e}} /\left(\mathrm{mg} \mathrm{g}^{-1}\right)$ & 44.6 & 1111.1 & 1111.1 \\
\hline $\mathrm{R}^{2}$ & 0.9993 & 0.9996 & 0.9998 \\
\hline Experimental $\mathrm{q}_{\mathrm{e}} /\left(\mathrm{mg} \mathrm{g}^{-1}\right)$ & 44.5 & 1146.5 & 1120.5 \\
\hline \multicolumn{4}{|c|}{ Potassium } \\
\hline $\mathrm{k}_{\mathrm{II}} / \min ^{-1}$ & $3.657 \times 10^{-3}$ & $1.199 \times 10^{-3}$ & $4.167 \times 10^{-4}$ \\
\hline $\mathrm{q}_{\mathrm{e}} /\left(\mathrm{mg} \mathrm{g}^{-1}\right)$ & 625.0 & 1666.67 & 2000.0 \\
\hline $\mathrm{R}^{2}$ & 0.9999 & 0.9997 & 0.9999 \\
\hline Experimental $\mathrm{q}_{\mathrm{e}} /\left(\mathrm{mg} \mathrm{g}^{-1}\right)$ & 623.0 & 1788.9 & 1914.1 \\
\hline
\end{tabular}

$\mathrm{t}$ : time: $\mathrm{q}_{\mathrm{e}}$ : ion desorbed at equilibrium time $\mathrm{t} ; \mathrm{q}_{\mathrm{t}}$ : ion desorbed at time $\mathrm{t}$; $\mathrm{k}$ : desorbed rate constant; $\mathrm{R}^{2}$ : coefficient of determination. 
produce fertilizer is a rational approach for the crucial task of food and renewable energy efficient production.

\section{Acknowledgments}

Financial support for this work was provided by Conselho Nacional de Desenvolvimento Científico e Tecnológico (CNPq) and Coordenação de Aperfeiçoamento de Pessoal de Nível Superior (CAPES). The authors are grateful to Empresa Urbano Agroindústria from the city of Jaraguá do Sul (Santa Catarina, Brazil) for providing the rice husk ash used in this study.

\section{References}

1. Ni, B.; Liu, M.; Lü, S.; Xie, L.; Wang, Y.; J. Agric. Food Chem. 2011, 59, 10169.

2. Chawakitchareon, P.; Anuwattana, R.; Buates, J. In Advanced Materials: Manufacturing, Physics, Mechanics and Applications - Springer Proceedings in Physics; Parinov, I. A.; Chang, S.-H.; Topolov, V. Y., eds.; Springer International Publishing Switzerland: Cham, Switzerland, 2016, p. 129-137.

3. Wu, L.; Liu, M.; Ind. Eng. Chem. Res. 2007, 46, 6494.

4. Amtmann, A.; Rubio, F. In $e L S$; John Wiley \& Sons, Ltd: New York, USA, 2001. DOI: 10.1002/9780470015902.a0023737.

5. Guntzer, F.; Keller, C.; Meunier, J.-D.; Agron. Sustainable Dev. 2012, 32, 201.

6. Epstein, E.; Ann. Appl. Biol. 2009, 155, 155.

7. Epstein, E.; Proc. Natl. Acad. Sci. U. S. A. 1994, 91, 11.

8. Dayanandan, P.; Kaufman, P. B.; Franklin, C. I.; Am. J. Bot. 1983, 70, 1079 .

9. Sun, L.; Gong, K.; Ind. Eng. Chem. Res. 2001, 40, 5861.

10. Champagne, E. T.; Rice: Chemistry and Technology, $3^{\text {rd }}$ ed.; American Association of Cereal Chemists: St. Paul, Minnesota, USA, 2004.
11. Pode, R.; Renewable Sustainable Energy Rev. 2016, 53, 1468.

12. Chandrasekhar, S.; Satyanarayana, K. G.; Pramada, P. N.; Raghavan, P.; Gupta, T. N.; J. Mater. Sci. 2003, 38, 3159.

13. Rietveld, H. M.; J. Appl. Crystallogr. 1969, 2, 65.

14. Larson, A. C.; Von Dreele, R. B.; Report LAUR 86-748: General Structure Analysis System (GSAS); Los Alamos National Laboratory: Los Alamos, NM, USA, 2004.

15. Toby, B. H.; J. Appl. Crystallogr. 2001, 34, 210.

16. Kalapathy, U.; Proctor, A.; Shultz, J.; Bioresour. Technol. 2002, $85,285$.

17. Fernandes, A. A.; Frajndlich, E. U. C.; Riella, H. G.; Mater. Sci. Forum 2005, 498-499, 676.

18. Mangrich, A.; Tessaro, L.; Anjos, A. D.; Wypych, F.; Soares, J.; Environ. Geol. 2001, 40, 1030.

19. Helrich, K.; Official Methods of Analysis of the Association of Official Analytical Chemists, Food Composition, Additives, Natural Contaminants, vol. 2; AOAC: Arlington, VA, USA, 1990.

20. Ho, Y. S.; McKay, G.; Process Biochem. 1999, 34, 451.

21. Ho, Y. S.; McKay, G.; Water Res. 1999, 33, 578.

22. Ho, Y. S.; McKay, G.; Water Res. 2000, 34, 735.

23. Karthikeyan, T.; Rajgopal, S.; Miranda, L. R.; J. Hazard. Mater. 2005, 124, 192.

24. Kapur, P. C.; Powder Technol. 1985, 44, 63.

25. Mangrich, A.; Tessaro, L.; Anjos, A. D.; Wypych, F.; Soares, J.; Environ. Geol. 2001, 40, 1030.

26. Ma, X.; Ma, H.; Yang, J.; Ind. Eng. Chem. Res. 2016, 55, 10926.

27. Kosorukov, A. A.; Nadel, L. G.; Russ. J. Inorg. Chem. 1985, 7 , 961.

28. Gregorkiewitz, M.; Li, Y.; White, T. J.; Withers, R. L.; Sobrados, I.; Can. Mineral. 2008, 46, 1511.

Submitted: February 27, 2017

Published online: April 18, 2017 